\title{
Clinical Evaluation of Everolimus in the Treatment of Neuroendocrine Tumors of the Lung: Patient Selection and Special Considerations. A Systematic and Critical Review of the Literature
}

This article was published in the following Dove Press journal:

Lung Cancer: Targets and Therapy

\author{
Marta Peri (iD) \\ Nicola Fazio $\mathbb{D}^{2}$ \\ 'Medical Oncology, Department of \\ Surgical, Oncological and Stomatological \\ Sciences, University of Palermo, Palermo, \\ Italy; ${ }^{2}$ Division of Gastrointestinal \\ Medical Oncology and Neuroendocrine \\ Tumors, European Institute of Oncology, \\ IEO, IRCCS, Milan, Italy
}

\begin{abstract}
Neuroendocrine tumors (NETs) of the lung are well-differentiated neuroendocrine neoplasms (NENs) with a heterogeneous clinical behaviour. Unlike gastroenteropancreatic NENs where therapeutic armamentarium clearly increased over the last decade, everolimus represented the only clinical practical innovation for lung NET patients over the last years. Therefore, for lung NETs, a multidisciplinary discussion within a dedicated team remains critical for an adequate decision-making. Although the main regulatory authorities considered the everolimus-related evidence is enough to approve the drug in advanced lung NETs, several clinical features deserve to be discussed. In this review, we systemically and critically analysed the main clinical studies including patients with advanced lung NETs receiving everolimus. Furthermore, we reported the biological and clinical background of everolimus in lung NET setting. The purpose of this review is to help clinical community to contextualize evidence and experience for a personalised use of this drug in clinical practice in the context of advanced lung NET patients.
\end{abstract}

Keywords: lung NET, typical carcinoid, atypical carcinoid, everolimus, mammalian target of rapamycin (mTOR) inhibitor, targeted agents

\section{Introduction}

Neuroendocrine neoplasms (NENs) are relatively rare and heterogeneous malignancies originating from cells of the diffuse neuroendocrine system, widely dispersed in the body. They comprise a wide range of grade of malignancy, from very indolent to rapidly proliferative. By extrapolating from the gastroenteropancreatic (GEP) tract terminology more in general the well-differentiated (WD) NENs can be named tumors (NETs) whereas the poorly differentiated (PD) are carcinomas (NECs) also in the lung.

In accordance with the 2015 WHO lung NEN classification lung NETs represent the low/intermediate grade by comprising typical (T) and atypical carcinoids (AC) whereas large cells and small cells lung NECs are the high-grade forms. ${ }^{1}$

Depending on symptoms due to the hypersecretion of hormones/amines by the tumor, lung NETs can be distinguished in functioning or non-functioning. The carcinoid syndrome is the most common clinical syndrome associated with a lung NET. ${ }^{2,3}$

Lung NETs are usually managed similarly to GEP NETs. However while in GEP NETs several new treatments have been approved over the last years, everolimus (EVE) is the only drug ever approved by FDA/EMA specifically for lung
Correspondence: Nicola Fazio via Ripamonti 435, Milan 2014I, Italy Tel +390257489439

Fax +390294379224

Email nicola.fazio@ieo.it 
NETs. However other drugs can be used in clinical practice despite they were not specifically approved for lung NETs, including somatostatin analogues (SSAs), chemotherapy, liver-directed treatments. Furthermore other therapies can be proposed within clinical trials, such as peptide receptor radionuclide therapy (PRRT).

In this review, we had focussed on clinical and biological features of advanced NETs of the lung treated with EVE.

\section{Materials and Methods}

\section{Identification}

A comprehensive literature search was designed and conducted by an experienced medical librarian with input from the study investigators. We searched the electronic databases Ovid MEDLINE, Embase and Scopus. Various combinations of database-specific controlled vocabulary (subject headings) were used, supplemented by keywords, title and abstract terms for the concepts and synonyms relating to neuroendocrine tumor, neuroendocrine tumors, neuroendocrine tumor, neuroendocrine tumors, neuroendocrine neoplasm, neuroendocrine neoplasms, carcinoid tumor or carcinoid tumors and lung, pulmonary, bronchopulmonary, broncho-pulmonary or bronchial and everolimus, rad001, m-tor inhibitor, m-tor inhibitors, mammalian target of rapamycin inhibitor or mammalian target of rapamycin inhibitors. Last updated literature search was performed on December 30th, 2019.

\section{Screening}

Literature search results in records. Record screening was performed in order to include patients with advanced welldifferentiated pulmonary NETs treated with EVE. Review articles, preclinical studies and book chapters were excluded. English language restriction was applied.

\section{Eligibility}

Eligible studies were selected by reviewing the full-text articles.

Studies including advanced pulmonary NETs receiving EVE with palliative intent were eligible.

Studies exploring the role of EVE in combination with other therapies such as with PRRT, chemotherapy, SSA, interferon (IFN) or local therapies were considered eligible.

Studies exploring the role of other therapies such as PRRT, chemotherapy or SSA or IFN without EVE were considered ineligible.
Studies were required to report tumor response and survival data.

Length of follow-up should be more than 3 months.

Prospective clinical trials and retrospective analysis of prospective trials were eligible; clinical trials or case series with less than 10 patients were excluded. If results were given for a population of mixed poorly and welldifferentiated NETs, these studies were excluded. Patients treated with adjuvant intent were not included in the qualitative synthesis.

\section{Qualitative Description}

Clinical and methodological data were extracted from the eligible studies.

Details of the study design, therapy regimen, prior therapies, histological typing, patient characteristics, side effects ad length of follow-up were collected.

\section{The Biological Landscape of Neuroendocrine Tumor of the Lung Pathologic and Phenotypic Features}

Lung NETs show the neuroendocrine (NE) morphology and derive from the mature cells of the pulmonary diffuse NE system. ${ }^{4,5}$

Mitoses and necrosis are essential for classifying TC and AC. ${ }^{1}$ Immunohistochemistry can be very helpful considering its constant positive staining for cytokeratin, neuroendocrine markers as chromogranin A (CgA), synaptophysin (SYN) and neuron-specific enolase (NSE). ${ }^{6}$

The Ki-67 is not necessary to classify lung NETs but its level can be useful in distinguishing between WD and PD forms, especially in limited diagnostic material, ${ }^{1,7,8}$ and it could have a prognostic role..$^{9-13}$

The functional expression of somatostatin receptors (SSTRs) is usually detected through a positron emission tomography/computed tomography (PET/CT) with ${ }^{68} \mathrm{Ga}-$ DOTA-peptide or, if not available, a somatostatin receptor scintigraphy (SRS). ${ }^{14}$ These nuclear medicine techniques play an important role in the staging, ${ }^{15,16}$ detection of recurrence, ${ }^{17}$ prediction of the response to PRRT, ${ }^{18}$ prediction of positive prognosis, ${ }^{19}$ therefore lead to a better clinical management. ${ }^{20,21}$

By contrast, the value of PET/CT with ${ }^{18}$ F-fluorodeoxyglucose (FDG) is still controversial. Some studies reported that the standardized uptake value is generally higher in $\mathrm{AC}$, demonstrating that FDG PET is helpful in predicting the behaviour of lung NETs. ${ }^{22-25}$ 
Evidence about the clinical utility of circulating biomarkers in lung NET is lacking. Despite the low specificity and the very poor level of evidence, plasma chromogranin $\mathrm{A}(\mathrm{CgA})$ in lung NET is the most used marker at baseline and in the follow-up. ${ }^{2,26}$ Elevated level of plasma $\mathrm{CgA}$ is usually associated with an advanced disease and with indolent disease. ${ }^{27,28}$ Novel markers, such as circulating tumor DNA, circulating tumor cells, circulating miRNAs and measurements of multianalyte transcript analysis appear to represent the most promising strategy in lung $\mathrm{NET}^{26}$

\section{Epidemiologic and Clinical Features}

Compared with lung NECs lung NETs occur predominantly in female, younger and non-smoker patients and they have a better prognosis. ${ }^{2,29}$

Typical carcinoid is ten times more common than AC and develops metastatic lesions in up to $15 \%$ of cases with a median time to recurrence of 4 years. Atypical carcinoid is metastatic in up to one half of cases with a median time to recurrence of 1.8 years. ${ }^{2}$

Synchronous metastases are present in $28 \%$ of lung NET patients, ${ }^{30}$ and metachronous metastases may develop even many years after surgical removal of the primary tumor and regional nodes, ${ }^{30-34}$ hence justifying a long-term surveillance even up to 15 years. $^{2,35,36}$

Metastases usually occur in regional lymph nodes but also distantly to the liver, bones, lung, distant lymph node and subcutis. ${ }^{27,32,37}$

Although lung NETs are usually slow-growing malignancies, the prognosis of distant metastases disease is relatively poor. However metastatic survival data are lacking and have been mainly extracted from SEER database analysis $^{30,36}$ and retrospective analyses. ${ }^{32,38,39}$

Moreover most of survival data have been collected considering the whole stage population (localized, regional, and distant metastatic) or have been extracted from surgical databases. ${ }^{40-44}$

The latest ESMO guidelines summarize these data reporting that TC patients have a 5-year survival rate of $87-90 \%$, much higher than that of $\mathrm{AC}$, that is $44-78 \%{ }^{35}$

Median survival from diagnosis of advanced lung NET patients is 6-7 years, as reported in three retrospective studies. $^{27,32,45}$

Several prognostic factors have been associated with poor survival in the metastatic setting, however more efforts should be made to identify univocal results and consequently improve patient selection. To date several independent clinical prognostic factors were described, such as age, poor ECOG PS, histotype, tumor size, symptoms, high $\mathrm{CgA}$ levels, negative SRS, presence of bone metastasis, liver metastasis, $\mathrm{Ki}-67$ as a continuous variable and lower time to relapse. ${ }^{27,32,41,44,46}$

\section{Rationale of mTOR Inhibitors in Lung NETs}

Lung NETs present a few genetic abnormalities compared with NECs, especially regarding chromatin-remodelling genes and DNA repair pathways. ${ }^{47-49}$ The most frequently mutated somatic genes are reported in Table 1.

The mammalian target of rapamycin (mTOR) is a serine/threonine kinase and is the catalytic subunit of two functionally distinct multiprotein complexes, mTOR complex 1 (mTORC1) and 2 (mTORC2).

The mTOR is activated via phosphorylation, following activation of an upstream signaling cascade, the

Table I Somatically Mutated Gene in Lung Neuroendocrine Tumors

\begin{tabular}{|c|c|}
\hline Mutated Gene & Significance of the Molecular Alterations \\
\hline MEN-I ${ }^{47-49}$ & $\begin{array}{l}\text { Gene that products Menin, a protein that } \\
\text { interacts with chromatin-associated protein } \\
\text { complexes and also regulates some non-coding } \\
\text { RNAs, participating in epigenetic control } \\
\text { mechanisms }\end{array}$ \\
\hline E3-Ub ligases ${ }^{47}$ & $\begin{array}{l}\text { Gene involved in Protein ubiquitination as } \\
\text { posttranslational modification }\end{array}$ \\
\hline ARID family ${ }^{47,49}$ & $\begin{array}{l}\text { Genes involved in the SWI-SNF complex and } \\
\text { chromatin remodeling }\end{array}$ \\
\hline KMT2 family 47,48 & $\begin{array}{l}\text { Genes involved in covalent histone } \\
\text { modification/chromatin remodeling }\end{array}$ \\
\hline SMARCA $4^{47}$ & Genes involved in chromatin remodeling \\
\hline HNFIA ${ }^{47}$ & $\begin{array}{l}\text { Gene that regulated the expression of acute } \\
\text { phase proteins and interleukin I receptor, } \\
\text { which are involved with inflammation and might } \\
\text { play a possible tumor suppressor role }\end{array}$ \\
\hline FOXA $3^{47}$ & $\begin{array}{l}\text { Genes involved in covalent histone } \\
\text { modification/chromatin remodeling }\end{array}$ \\
\hline $\mathrm{PSIPI}^{49}$ & Genes involved in chromatin remodeling \\
\hline $\begin{array}{l}\mathrm{PI} 3 \mathrm{~K} / \mathrm{AKT} / \mathrm{mTOR} \\
\text { pathway }{ }^{48}\end{array}$ & $\begin{array}{l}\text { Pathway involved in intracellular signaling } \\
\text { pathway important in regulating the cell cycle }\end{array}$ \\
\hline
\end{tabular}


phosphoinositide 3-kinase (PI3K)/AKT/mTOR pathway, that is important in regulating the cell cycle.

Everolimus, also known as RAD001, is an oral derivative of rapamycin, which has shown a potent inhibitory activity of the mTORC1 in primary cultures of human $\mathrm{NET}^{50}$ and proven efficacy in lung NETs. Lung NETs exhibit genetic abnormalities located in the PI3K/AKT/mTOR pathway causing the upregulation of mTOR signaling components or downregulation of its upstream negative regulators. ${ }^{48,51-53}$

Furthermore, deregulation of PI3K and loss of function of PTEN can predict response to mTOR inhibitors $^{54-56}$ and lower level of mTOR, p70S6K and Akt were described as potential predictive markers of resistance. ${ }^{51,57}$

Considering the overexpression of pro-angiogenic molecules and of tyrosine kinase receptors (TKRs), the rationale of EVE in lung NET is also based on its involvement in angiogenesis process (regulating the activity of hypoxia-inducible factor alpha, HIF- $\alpha$, and the expression of VEGF and PDGF-b) ${ }^{58}$ and in tyrosine kinase activation (EGFR, IGFR and FGFR-3).

\section{Clinical Evaluation of Everolimus Treatment in Neuroendocrine Tumor of the Lung Results of Literature Review}

Records identified through literature search were 610:123 from MEDLINE searching, 357 from Embase and 130 from Scopus.

The total number of manuscripts screened was 97 .

On the basis of the aforementioned criteria of selection, eligible studies included in the final analysis were 6 (Table 2, Supplementary Figure 1). ${ }^{59-65}$

All but one included thoracic and extra-thoracic populations. Three were randomised controlled trials (RCTs), two Phase III and one Phase II. The LUNA trial was the only one specifically designed for patients with advanced lung/thymic NETs. It was a three-arm randomised Phase II trial comparing Pasireotide (PAS) with everolimus (EVE) with both. The other two randomised trials were double-arm placebocontrolled phase III randomised trials: the RADIANT- 2 for patients with carcinoid syndrome-associated NETs from any

Table 2 Key Characteristics of Eligible Studies

\begin{tabular}{|c|c|c|c|c|c|c|}
\hline $\begin{array}{l}\text { Study, Phase, First } \\
\text { Author (Year) }\end{array}$ & Treatment & $\begin{array}{l}\text { Primary } \\
\text { Site }\end{array}$ & $\begin{array}{l}\text { Lung NET (n)/ } \\
\text { Patients } \\
\text { Enrolled }\end{array}$ & $\begin{array}{l}\text { Lung NET } \\
\text { Treated with } \\
\text { Eve (n) }\end{array}$ & $\begin{array}{l}\text { Line of } \\
\text { Therapy }\end{array}$ & $\begin{array}{l}\text { Association } \\
\text { with SSA }\end{array}$ \\
\hline $\begin{array}{l}\text { RADIANT-2, Phase III } \\
\text { Pavel ME }(2011)^{59}\end{array}$ & $\begin{array}{l}\text { EVE } 10 \mathrm{mg}+\text { OCT LAR } 30 \mathrm{mg} \\
\text { or placebo + OCT LAR } 30 \mathrm{mg}\end{array}$ & Mixed NET & $44 / 429$ & 33 & ANY & $\begin{array}{l}\text { YES (I00\%) } \\
\text { (OCT LAR 30mg } \\
\text { q28) }\end{array}$ \\
\hline $\begin{array}{l}\text { Lung subgroup } \\
\text { analysis RADIANT-2, } \\
\text { phase III } \\
\text { Fazio N }(2013)^{60}\end{array}$ & $\begin{array}{l}\text { EVE } 10 \mathrm{mg}+\text { OCT LAR } 30 \mathrm{mg} \\
\text { or placebo + OCT LAR } 30 \mathrm{mg}\end{array}$ & Lung NET & $44 / 429$ & 33 & ANY & $\begin{array}{l}\text { YES (I00\%) } \\
\text { (OCT LAR 30mg } \\
\text { q28) }\end{array}$ \\
\hline $\begin{array}{l}\text { RADIANT-4, phase III } \\
\text { Yao JC }(20 \mid 5)^{61}\end{array}$ & EVE $10 \mathrm{mg}$ or placebo & Mixed NET & $90 / 302$ & 63 & $\begin{array}{l}\text { ANY } \\
(\text { IL 39\%) }\end{array}$ & $0 \%$ \\
\hline $\begin{array}{l}\text { Lung subgroup } \\
\text { analysis RADIANT-4, } \\
\text { phase III } \\
\text { Fazio N }(2017)^{62}\end{array}$ & EVE $10 \mathrm{mg}$ or placebo & Lung NET & $90 / 302$ & 63 & $\begin{array}{l}\text { ANY } \\
\text { (IL I4 vs } \\
\text { II) }\end{array}$ & $0 \%$ \\
\hline $\begin{array}{l}\text { ITMO, } \\
\text { Phase II } \\
\text { Bajetta E }(2014)^{63}\end{array}$ & EVE $10 \mathrm{mg}+$ OCT LAR $30 \mathrm{mg}$ & Mixed NET & $11 / 50$ & 11 & FIRST & $\begin{array}{l}\text { YES (I00\%) } \\
\text { (OCT LAR 30mg } \\
\text { q28) }\end{array}$ \\
\hline $\begin{array}{l}\text { LUNA, } \\
\text { Phase II } \\
\text { Ferolla }(2017)^{65}\end{array}$ & $\begin{array}{l}\text { PAS or EVE } 10 \mathrm{mg} \text { or } \\
\text { combination }\end{array}$ & $\begin{array}{l}\text { Lung and } \\
\text { thymus NET }\end{array}$ & $116 / 124$ & 78 & $\begin{array}{l}\text { IL (\%): } 29 \\
\text { vs } 36 \text { vs } \\
32\end{array}$ & $\begin{array}{l}\text { Only the } \\
\text { combination arm } \\
\text { (EVE+PAS) }\end{array}$ \\
\hline
\end{tabular}

Abbreviations: EVE, everolimus; OCT, Octreotide; NET, neuroendocrine tumor; SSA, somatostatin analogue; PAS, pasireotide. 
origin and RADIANT-4 for non-functioning non-pancreatic gastrointestinal and lung NETs.

Finally, the ITMO study was a prospective single-arm phase II and two studies were post hoc retrospective analyses from the RADIANT-2 and RADIANT-4.

Overall, 185 patients with lung NET received EVE within prospective trials (Table 3 )

\section{Patient Selection}

The inclusion criteria differed from study to study.

The RADIANT-2 enrolled only NETs associated with a carcinoid syndrome, from any primary site. The Ki-67 was not required as an inclusion criterion. Prior therapies were allowed. Neither stratification nor preplanned analysis for lung NETs were included in the design of the trial. Radiologic baseline progressive disease within the last 12 months, not necessarily RECISTbased, was required. With regards to the carcinoid syndrome inclusion criteria reported "history of symptoms attributed to carcinoid syndrome (flushing, diarrhea, or both)".

The RADIANT-4 included only non-functioning NETs, from GI or lung, with up to $20 \% \mathrm{Ki}-67$ (grade 1 or grade 2 in accordance with the WHO 2010 classification). Previous treatments were allowed. Radiologic baseline progressive disease within the last 6 months, not necessarily RECIST-based, was required.

While in the RADIANT-2 no stratification was planned for lung NETs, a prognostic stratification into two subgroups was decided in the RADIANT-4, by including lung NETs into the poor prognosis category, together with stomach, colon and rectum.

The ITMO study included just therapy-naïve (a true first-line) mixed population well differentiated, G1-2, NETs. No specific analysis for lung NETs was preplanned.

While in the aforementioned trials lung NETs could be included regardless of their definition of TC or AC, in the LUNA trial all included lung NETs had to be defined as $\mathrm{TC}$ or AC. The LUNA required a radiologic baseline progressive disease within the last 12 months, not necessarily RECIST-based. Patients with severe functioning disease requiring symptomatic treatment with SSA were ineligible and stratification was performed according to histology (TC versus AC) and to line of study treatment (first line of systemic medical treatment versus other).
No specific inclusion criteria regarded tumor burden in any trials.

\section{Efficacy Data}

Primary endpoints were progression-free survival (PFS) by central radiology review for the RADIANT-2 trial, PFS by real-time central radiology review for the RADIANT-4, 9-month PFS rate for the LUNA trial and overall response rate (ORR) for the ITMO study.

While RADIANT-4 and LUNA were positive studies according to their met statistical goal, RADIANT-2 was a negative study due to the unmet pre-specified threshold of $\mathrm{p}=0.024$.

No statistical significant improvement of OS was reported so far in favor of EVE from the two phase III RCTs.

Table 4 comprises all the efficacy data of the selected studies.

\section{Special Consideration: Which Tumor Population}

Median age (58-67 years), males (51-68\%), Caucasians (84-100\%) and WHO PS score of 0 (45.5-75\%) were similar from all the studies, except for ITMO study that enrolled only patients with PS of 0 .

Among the patients in whom tumor morphology was reported, the majority were TC, except for LUNA trial that selected a more aggressive tumor population.

The EVE-arm included lung NETs who had mainly been previously treated with other therapies whereas the rate of first-line treatment was $14-36 \%$.

Prior SSA therapy was administered in $43-46 \%$ of EVE treated population (except for RADIANT-2 trial that enrolled a higher percentage $(67 \%)$ of patients previously treated with SSA).

Radiotherapy, including PRRT, had been received before EVE in 19.5-40\% of patients.

The tumor burden of lung NET treated with EVE was described as presence of metastatic hepatic lesions (ranging from $68 \%$ to $81 \%)$ and elevated level of $\mathrm{CgA}(76 \%$ of cases in ITMO trial and $1278.8 \mathrm{ng} / \mathrm{mL}$ as median value in RADIANT-2).

Apart from RADIANT-2 and -4 , the others studies included patients with syndrome ranging from $17 \%$ to $29 \%$.

Table 5 comprises all the toxicities reported in the selected studies. 


\begin{tabular}{|c|c|c|c|c|c|}
\hline 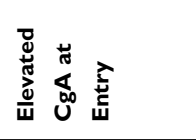 & 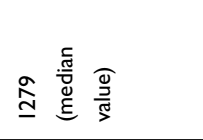 & 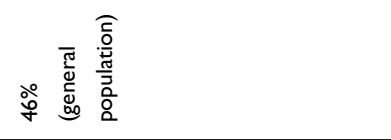 & 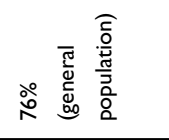 & $\frac{\alpha}{z}$ & $\frac{\alpha}{z}$ \\
\hline 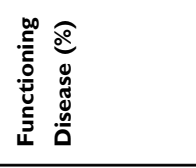 & 으 & $\circ$ & 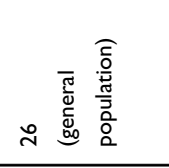 & $=$ & $\approx$ \\
\hline 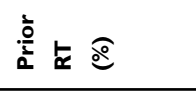 & $\frac{\alpha}{z}$ & o & 0 & $\stackrel{\sim}{\sim}$ & $\stackrel{\varrho}{\varrho}$ \\
\hline 嵩 & ले & లి & $\circ$ & $\stackrel{n}{a}$ & $\begin{array}{l}n \\
\infty \\
\infty \\
\infty\end{array}$ \\
\hline 高芯 & $\hat{0}$ & q & 。 & ๖ & $f$ \\
\hline 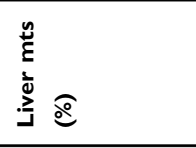 & 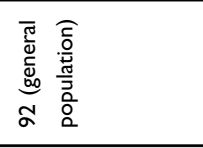 & $\begin{array}{c}m \\
\infty \\
\infty \\
\end{array}$ & $\stackrel{\alpha}{z}$ & $\bar{\infty}$ & 2 \\
\hline ఝ̆ & $\begin{array}{l}\stackrel{n}{\not} \\
\dot{q}\end{array}$ & $\stackrel{m}{\kappa}$ & 으 & in & ஃ \\
\hline 仓 & 号 & ‡ & 음 & 음 & $\stackrel{\infty}{\circ}$ \\
\hline $\begin{array}{l}\overparen{\varrho} \\
\frac{0}{\Sigma} \\
\end{array}$ & : & n & 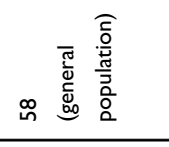 & 员 & $\infty$ \\
\hline 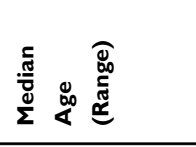 & 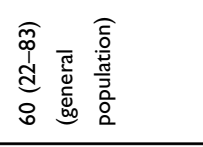 & $\begin{array}{l}\widehat{D} \\
\infty \\
c \\
0 \\
6\end{array}$ & 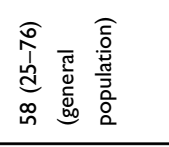 & $\begin{array}{l}\widehat{\widehat{N}} \\
\frac{1}{\infty} \\
\stackrel{0}{0}\end{array}$ & 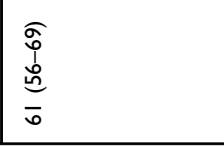 \\
\hline 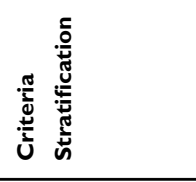 & 品 & 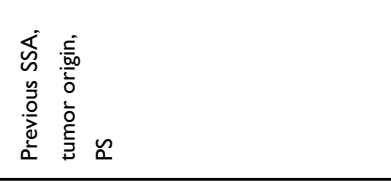 & 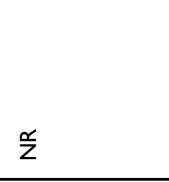 & \multicolumn{2}{|c|}{ 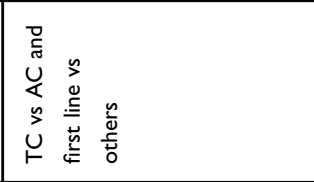 } \\
\hline 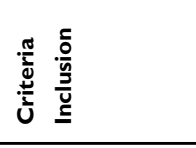 & 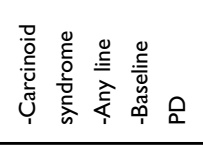 & 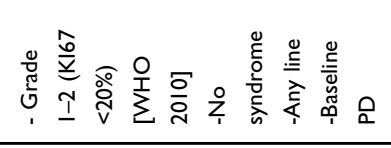 & 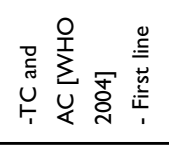 & \multicolumn{2}{|c|}{ 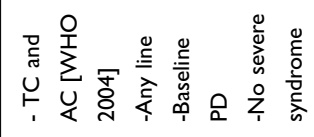 } \\
\hline ¿̊ ฮ & $\circ$ & $\stackrel{\infty}{n}$ & $\frac{\alpha}{z}$ & ○ & 0 \\
\hline ४ @ & $\underline{\infty}$ & r & $\stackrel{\alpha}{z}$ & $\pi$ & $\infty$ \\
\hline$\stackrel{U}{\circ}$ @ & 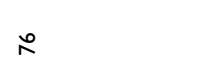 & $\stackrel{m}{m}$ & $\frac{\alpha}{z}$ & ลิ & $\approx$ \\
\hline 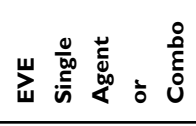 & $\begin{array}{l}5 \\
0 \\
+ \\
+\end{array}$ & 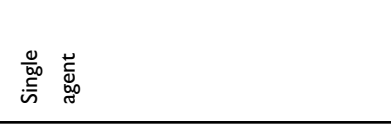 & $\begin{array}{l}5 \\
\circ \\
+ \\
+\end{array}$ & 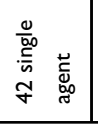 & 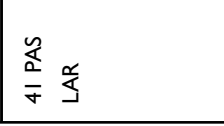 \\
\hline 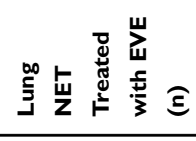 & m & 3 & $=$ & \multicolumn{2}{|c|}{ 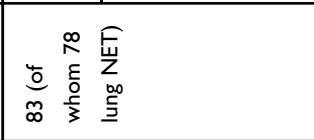 } \\
\hline 䓂 & 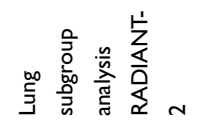 & 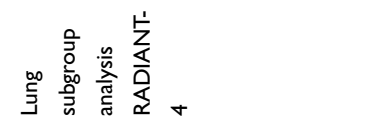 & $\sum_{E}^{O}$ & \multicolumn{2}{|c|}{ 志 } \\
\hline
\end{tabular}


Table 4 Efficacy Outcomes of Eligible Studies

\begin{tabular}{|c|c|c|c|c|c|c|c|c|}
\hline Study & Treatment & $\begin{array}{l}\text { Lung } \\
\text { NET } \\
\text { (n) }\end{array}$ & PR \% & DCR \% & $\begin{array}{l}\text { Tumor } \\
\text { Shrinkage } \\
\text { (\%) }\end{array}$ & mPFS (m) & HR & M-fu (m) \\
\hline $\begin{array}{l}\text { Lung subgroup } \\
\text { analysis } \\
\text { RADIANT-2 }\end{array}$ & $\begin{array}{l}\text { EVE } 10 \mathrm{mg}+\text { OCT LAR } \\
30 \mathrm{mg} \text { or placebo + OCT } \\
\text { LAR } 30 \mathrm{mg}\end{array}$ & 44 & 0 vs 0 & NR & 67 vs 27 & $\begin{array}{l}13.63 \text { vs } \\
5.59\end{array}$ & 0.72 & NR \\
\hline $\begin{array}{l}\text { Lung subgroup } \\
\text { analysis } \\
\text { RADIANT-4 }\end{array}$ & EVE $10 \mathrm{mg}$ or placebo & 90 & 2 vs 4 & 81 vs 59 & 58 vs 13 & 9.2 vs 3.6 & 0.50 & NR \\
\hline $\begin{array}{l}\text { ITMO 5-Year } \\
\text { Update }\end{array}$ & $\begin{array}{l}\text { EVE } 10 \mathrm{mg}+\text { OCT LAR } \\
30 \mathrm{mg}\end{array}$ & II & 9 (lung NET) & $\begin{array}{l}92 \text { (general } \\
\text { population)** }\end{array}$ & NR & $\begin{array}{l}33.6 \\
\text { (general } \\
\text { population) }\end{array}$ & NR & $\begin{array}{l}50 \text { (general } \\
\text { population) }\end{array}$ \\
\hline LUNA & $\begin{array}{l}\text { PAS or EVE } 10 \mathrm{mg} \text { or } \\
\text { combination }\end{array}$ & 116 & $\begin{array}{l}2.4 \text { vs } 2.4 \text { vs } \\
2.4^{*}\end{array}$ & $\begin{array}{l}36.5 \text { vs } 33.4 \text { vs } \\
51.2^{*}\end{array}$ & $\begin{array}{l}31 \text { vs } 49 \text { vs } \\
73\end{array}$ & $\begin{array}{l}8.5 \text { vs } 12.5 \\
\text { vs } 11.8\end{array}$ & NR & 12 \\
\hline
\end{tabular}

Notes: *Response at month 9. **The authors affirmed that subgroup analyses by tumor primary site did not show any significant difference in ORR.

Abbreviations: DCR, disease control rate (defined as rate of complete, partial and stable responses by radiological assessment, according to criteria employed at the time of the manuscript publication); OCT, octreotide, PAS, pasireotide; PR, partial response; PFS, progression-free survival; HR, hazard ratio; fu, follow-up; EVE, everolimus; NR, not reported.

\section{Special Consideration: Which Biomarker}

A recent study analyzed genomic profiling on tumor samples along with nongenomic biomarkers, including circulating $\mathrm{CgA}$ and NSE levels, from patients enrolled in the RADIANT-2, RADIANT-3 and RADIANT-4. Lung NET patients showed a significant correlation between PFS and chromosomal aberrations, in particular $\mathrm{LOH}$ in chromosome 3. This correlation was still significant after adjusting for tumor grade and baseline circulating levels of CgA and NSE. ${ }^{66}$

Studies selected in this review did not assess the potential prognostic or predictive role of soluble angiogenic biomarkers (VEGFR1, PIGF), as performed in the RADIANT-3 in the advanced pancreatic NET population. ${ }^{67}$ In a recent study ${ }^{68}$ higher baseline neutrophil-lymphocyte ratio (NLR) and lower (lymphocyte-monocyte ratio) LMR correlate with a shorter PFS in patients treated with EVE in NET population of the RADIANT-3 and RADIANT-4 trials. However in the lung subgroup analysis there was no trend observed, possibly due to the small number of patients in the group. A blood mRNA-based biomarker, the NETest, has been proposed as a multianalyte algorithmic tool for lung NET and may represent a promising strategy to establish a diagnosis and monitor therapeutic efficacy. ${ }^{69}$

\section{Special Consideration: Which Timing for EVE}

A post hoc analysis of the RADIANT-4 reported the effect of prior therapies on EVE activity demonstrating that EVE improved outcomes regardless of prior treatments. The safety profile of EVE was not impacted by the use of prior lines of therapies and was similar to that reported for the overall population analysis. ${ }^{70}$

In addition, limited retrospective studies showed data about sequence of therapies in mixed NET populations, including small number of patients with lung NET. ${ }^{27,32,71,72}$ Faggiano et al, suggested sequences with first-line SSA followed by SSA high-dose or PRRT as second-line treatment for mixed population NETs. Furthermore chemotherapy and targeted therapy should be then considered in case of further progression because of their worse tolerability. ${ }^{71}$ Panzuto et al performed a real-world analysis of NET patients treated with EVE suggesting that EVE should be planned before PRRT and chemotherapy to avoid predictable severe toxicities. ${ }^{72}$

Finally, the last two retrospective analyses were focused on lung NETs and provided an overview of the real-life clinical practice. ${ }^{27,32}$ Because of long recruitment period and consequent heterogeneity of patient management, the comparison between treatment strategies is precluded. Of note SSAs were the most commonly performed first-line therapy.

No absolute indication about the EVE timing in lung NET can be drawn from our analysis.

The European medicines agency (EMA) approved EVE in lung NETs with progressive disease without a restriction to a subgroup or a specific line of treatment.

As suggested in the ENETS guidelines EVE may be recommended as a first-line therapy in advanced lung NET 
Table 5 Grade 3 or 4 Everolimus-Adverse Events Occurred in Eligible Studies

\begin{tabular}{|c|c|c|c|c|c|c|}
\hline & $\begin{array}{l}\text { Lung Subgroup } \\
\text { Analysis RADIANT-2 } \\
\text { EVE Plus OCT LAR }\end{array}$ & $\begin{array}{l}\text { Lung Subgroup } \\
\text { Analysis } \\
\text { RADIANT-4 } \\
\text { EVE }\end{array}$ & $\begin{array}{l}\text { ITMO } \\
\text { EVE } \\
\text { Plus } \\
\text { OCT }\end{array}$ & $\begin{array}{l}\text { ITMO 5-Year } \\
\text { Update EVE } \\
\text { Plus OCT }\end{array}$ & $\begin{array}{l}\text { LUNA } \\
\text { EVE }\end{array}$ & $\begin{array}{l}\text { LUNA } \\
\text { EVE } \\
\text { Plus } \\
\text { PAS }\end{array}$ \\
\hline Stomatitis & $23(69.7 \%)$ & 7 (II.3\%) & $5(10 \%)$ & $4(8 \%)$ & $4(10 \%)$ & $2(5 \%)$ \\
\hline Rash & II (33.3\%) & 0 & I (2\%) & I (2\%) & $3(7 \%)$ & $N R$ \\
\hline Fatigue & $4(12.1 \%)$ & $2(3.2 \%)$ & NR & $N R$ & I (2\%) & $4(10 \%)$ \\
\hline Diarrhoea & $9(27.3 \%)$ & $3(4.8 \%)$ & II (22\%) & $4(8 \%)$ & $3(7 \%)$ & $8(19 \%)$ \\
\hline Nausea & $4(12.1 \%)$ & $2(3.2 \%)$ & NR & NR & I (2\%) & NR \\
\hline Infections & $N R$ & 5 (7.1\%) & I (2\%) & $N R$ & NR & $N R$ \\
\hline Dysgeusia & $4(12.1 \%)$ & 0 & NR & NR & 0 & NR \\
\hline Anaemia & $5(15.2 \%)$ & $2(3.2 \%)$ & I (2\%) & I (2\%) & I (2\%) & $2(5 \%)$ \\
\hline Leukopenia & $4(12.1 \%)$ & NR & I (2\%) & I (2\%) & NR & NR \\
\hline Decreased weight & $4(12.1 \%)$ & $\mathrm{I}(\mathrm{I} .6 \%)$ & NR & NR & I (2\%) & $3(7 \%)$ \\
\hline Thrombocytopenia & $6(18.2 \%)$ & NR & NR & $N R$ & I (2\%) & NR \\
\hline Decreased appetite & $4(12.1 \%)$ & 0 & NR & NR & $2(5 \%)$ & $2(5 \%)$ \\
\hline Peripheral oedema & NR & $2(3.2 \%)$ & NR & $N R$ & I (2\%) & I (2\%) \\
\hline Hyperglycaemia & $5(15.2 \%)$ & $6(9.8 \%)$ & NR & NR & $7(17 \%)$ & $10(24 \%)$ \\
\hline Dyspnoea & $5(15.2 \%)$ & $\mathrm{I}(\mathrm{I} .6 \%)$ & NR & NR & $2(5 \%)$ & $2(5 \%)$ \\
\hline Pulmonary events & NR & I (I. 6\%) & NR & NR & $3(7 \%)$ & $2(5 \%)$ \\
\hline Vomiting & NR & NR & NR & NR & NR & $\mathrm{I}(2 \%)$ \\
\hline Pruritus & $4(12.1 \%)$ & $\mathrm{I}(\mathrm{I} .6 \%)$ & NR & $N R$ & NR & NR \\
\hline Asthenia & $8(24.2 \%)$ & $\mathrm{I}(\mathrm{I} .6 \%)$ & NR & $N R$ & I (2\%) & I (2\%) \\
\hline Erythema & $5(15.2 \%)$ & NR & NR & NR & NR & NR \\
\hline Pyrexia & NR & $2(3.2 \%)$ & NR & NR & I (2\%) & NR \\
\hline Hypercholesterolemia & NR & NR & NR & I (2\%) & NR & NR \\
\hline Hypokalemia & NR & NR & NR & $4(8 \%)$ & NR & NR \\
\hline Hypertriglyceridemia & NR & NR & NR & I (2\%) & NR & I (2\%) \\
\hline Hyponatremia & NR & NR & NR & I (2\%) & NR & NR \\
\hline Acute myocardial infarction & NR & NR & NR & $\mathrm{I}(2 \%)$ & NR & NR \\
\hline Constipation & NR & NR & NR & NR & I (2\%) & NR \\
\hline Blood alkaline phosphatase increased & NR & NR & NR & NR & I (2\%) & I (2\%) \\
\hline$\gamma$-glutamyltransferase increased & NR & NR & NR & NR & $3(7 \%)$ & $3(7 \%)$ \\
\hline Hypophosphataemia & NR & NR & NR & NR & $2(5 \%)$ & $\mathrm{I}(2 \%)$ \\
\hline Mouth ulceration & NR & NR & NR & NR & I (2\%) & $\mathrm{I}(2 \%)$ \\
\hline
\end{tabular}


Table 5 (Continued).

\begin{tabular}{|c|c|c|c|c|c|c|}
\hline & $\begin{array}{l}\text { Lung Subgroup } \\
\text { Analysis RADIANT-2 } \\
\text { EVE Plus OCT LAR }\end{array}$ & $\begin{array}{l}\text { Lung Subgroup } \\
\text { Analysis } \\
\text { RADIANT-4 } \\
\text { EVE }\end{array}$ & $\begin{array}{l}\text { ITMO } \\
\text { EVE } \\
\text { Plus } \\
\text { OCT }\end{array}$ & $\begin{array}{l}\text { ITMO 5-Year } \\
\text { Update EVE } \\
\text { Plus OCT }\end{array}$ & $\begin{array}{l}\text { LUNA } \\
\text { EVE }\end{array}$ & $\begin{array}{l}\text { LUNA } \\
\text { EVE } \\
\text { Plus } \\
\text { PAS }\end{array}$ \\
\hline Haemorrhoids & NR & NR & NR & NR & I $(2 \%)$ & NR \\
\hline Flushing & NR & NR & NR & NR & I $(2 \%)$ & NR \\
\hline Diabetes mellitus & NR & NR & NR & NR & NR & $3(7 \%)$ \\
\hline Chest pain & NR & NR & NR & NR & NR & I (2\%) \\
\hline Aspartate aminotransferase increased & NR & NR & NR & NR & NR & $\mathrm{I}(2 \%)$ \\
\hline Dysphagia & NR & NR & NR & NR & $2(5 \%)$ & NR \\
\hline General physical health deterioration & NR & NR & NR & NR & I (2\%) & NR \\
\hline Pulmonary embolism & NR & NR & NR & NR & I $(2 \%)$ & $2(5 \%)$ \\
\hline
\end{tabular}

Abbreviations: NR, not reported; OCT, octreotide; PAS, pasireotide.

with progressive disease. However, in patients with low proliferative activity (G1, typical carcinoid) with strong SSTR expression on imaging, preferably with $\mathrm{Ki}-67<10 \%$, an SSA may be preferred to EVE as first-line therapy (Table 3).

The same guidelines reported that temozolomide-based chemotherapy may be considered in NET G3 and in highrisk pulmonary $\mathrm{NET}^{73}$

\section{Special Consideration: Effect on Tumor Shrinkage}

Tumor shrinkage can be a goal in case of future surgical approach or mass-effect symptoms control. Data about tumor shrinkage, in lung NET treated with EVE are reported in Table 4. Everolimus is not considered a strong cytoreductive drug in NETs more in general. Similarly in lung NETs, the reported partial response (PR) rate is very low; however a remarkable percentage of patients treated with EVE achieved some grade of tumor shrinkage, as reported in the waterfall plots.

\section{Special Consideration: EVE \pm SSA}

Octreotide and lanreotide are the only two SSAs usable in clinical practice, also for non-functioning lung NETs. Pasireotide is just investigational.

Provided that in functioning NETs an SSA should be done for syndrome control an open debate remains about the EVE + SSA in non-functioning NETs.

The role of SSA in reducing the expression of insulin-like growth factors (IGF) and epidermal growth factor (EGF) along with EVE suggests the hypothesis that these two drugs work synergistically to arrest cell growth and to control hypersecretory activity in NETs. ${ }^{74}$ However, despite the strong biological rationale, there are no absolute clinical data to propose the combination of EVE and available SSAs in nonfunctioning lung NETs.

Although the LUNA study showed that EVE + PAS LAR was active and potential effective no practical conclusions can be drawn from that due to the type of study and unfortunately no further investigational plan exists to check the efficacy of this combo in lung NETs.

\section{Special Consideration: EVE in Functioning Lung NETs}

Although from the analysed studies a clinical impact of EVE + OCT LAR can be supposed also in functioning lung NETs EVE was approved just for non-functioning lung NETs due to the unmet statistical endpoint of the RADIANT-2 trial.

While EVE is utilized in NETs for tumor growth control, recent studies supported its use also for syndrome control in refractory functioning NETs. ${ }^{75,76}$

Furthermore it should be considered that in the LUNA trial $23 \%(\mathrm{n}=28)$ functioning lung and thymus carcinoids were included. Similarly in the ITMO study $26 \%(n=13)$ functioning NETs were included and the first-line EVE +OCT LAR combo resulted active regardless of the presence or absence of carcinoid syndrome. 


\section{Conclusion}

To date no therapy can be considered as a standard of care for patients with an advanced lung NET. Everolimus is the only drug specifically approved for lung NETs, although this approval was based on the positive results of a large-randomised phase III trials including a mixed population of GI and lung NETs and it regarded just the nonfunctioning NETs. SSAs are recommended for functioning lung NETs but they are allowed to be proposed also for non-functioning lung NETs despite they were approved as antiproliferative agents just for GEP NETs. PRRT is investigational for lung NETs whereas it was approved for all GEP NETs. In many Countries temozolomide or other chemotherapeutic agents are allowed to be proposed for lung NETs even without specific evidence and approval. Liver-directed treatments, surgical and not surgical, are usually discussed as in GEP setting, outside specific evidence.

So far no specific sequence or integration of therapies have been validated for advanced lung NETs.

On this basis in clinical practice EVE, the only specifically approved drug for lung NETs, should be managed among this heterogeneous therapeutic landscape. Therefore, it is advisable that each clinical case is discussed within a NET-dedicated multidisciplinary team (MDT) and a therapeutic strategy rather than a single therapy choice is shared. Evidence, guidelines, goals of treatment are all critical factors to be considered to make an adequate clinical decision.

There is evidence to consider EVE as first-line or furtherline therapy in nonfunctioning progressive advanced lung NETs. Although there is not evidence against the use of EVE in naïve patients with lung NET however data are more solid for pre-treated patients, mainly with SSA.

Clinical data about a combination of EVE + SSA in non-functioning lung NETs are poor and not solid.

Despite the negative statistical results but apparently positive clinical impact of the RADIANT-2 trial EVE + SSA could be considered in selected cases of advanced functioning lung NETs resistant to SSA, provided that it is allowed by local regulatory authorities.

\section{Acknowledgments}

We thank Mr William Russell-Edu for supporting us for the design and the conduction of the comprehensive literature search.

\section{Disclosure}

Dr Nicola Fazio reports personal fees and research funds to the institution from Novartis, AAA and Ipsen, and personal fees from Pfizer. The authors report no other conflicts of interest in this work.

\section{References}

1. Travis WD, Brambilla E, Nicholson AG, et al. The 2015 World Health Organization classification of lung tumors: impact of genetic, clinical and radiologic advances since the 2004 classification. $J$ Thorac Oncol. 2015;10(9):1243-1260. doi:10.1097/JTO.000000 0000000630

2. Caplin ME, Baudin E, Ferolla P, et al. Pulmonary neuroendocrine (carcinoid) tumors: European Neuroendocrine Tumor Society expert consensus and recommendations for best practice for typical and atypical pulmonary carcinoids. Ann Oncol. 2015;26(8):1604-1620. doi:10.1093/annonc/mdv041

3. Halperin DM, Shen C, Dasari A, et al. Frequency of carcinoid syndrome at neuroendocrine tumour diagnosis: a population-based study. Lancet Oncol. 2017;18(4):525-534. doi:10.1016/S14702045(17)30110-9

4. Linnoila RI. Functional facets of the pulmonary neuroendocrine system. Lab Invest. 2006;86(5):425-444. doi:10.1038/labinvest.3700412

5. Warburton D, Schwarz M, Tefft D, Flores-Delgado G, Anderson KD, Cardoso WV. The molecular basis of lung morphogenesis. Mech Dev. 2000;92(1):55-81. doi:10.1016/S0925-4773(99)00325-1

6. Warren WH, Memoli VA, Gould VE. Immunohistochemical and ultrastructural analysis of bronchopulmonary neuroendocrine neoplasms. I. Carcinoids. Ultrastruct Pathol. 1984;6(1):15-27. doi:10.3109/01913128409016661

7. Volante M, Gatti G, Papotti M. Classification of lung neuroendocrine tumors: lights and shadows. Endocrine. 2015;50(2):315-319.

8. Pelosi G, Rodriguez J, Viale G, Rosai J. Typical and atypical pulmonary carcinoid tumor overdiagnosed as small-cell carcinoma on biopsy specimens: a major pitfall in the management of lung cancer patients. Am J Surg Pathol. 2005;29(2):179-187. doi:10.1097/01. pas.0000149690.75462.29

9. Rindi G, Klersy C, Inzani F, et al. Grading the neuroendocrine tumors of the lung: an evidence-based proposal. Endocr Relat Cancer. 2013;21(1):1-16. doi:10.1530/ERC-13-0246

10. Zahel T, Krysa S, Herpel E, et al. Phenotyping of pulmonary carcinoids and a Ki-67-based grading approach. Virchows Arch. 2012;460 (3):299-308. doi:10.1007/s00428-012-1194-2

11. Walts AE, Ines D, Marchevsky AM. Limited role of Ki-67 proliferative index in predicting overall short-term survival in patients with typical and atypical pulmonary carcinoid tumors. Mod Pathol. 2012;25(9):1258-1264. doi:10.1038/modpathol.2012.81

12. Grimaldi F, Muser D, Beltrami CA, et al. Partitioning of bronchopulmonary carcinoids in two different prognostic categories by ki-67 score. Front Endocrinol (Lausanne). 2011;2:20. doi:10.3389/fendo.2011.00020

13. Swarts DR, Rudelius M, Claessen SM, et al. Limited additive value of the Ki-67 proliferative index on patient survival in World Health Organization-classified pulmonary carcinoids. Histopathology. 2017;70(3):412-422. doi:10.1111/his.13096

14. Granberg D, Sundin A, Janson ET, Oberg K, Skogseid B, Westlin JE. Octreoscan in patients with bronchial carcinoid tumours. Clin Endocrinol (Oxf). 2003;59(6):793-799. doi:10.1046/ j.1365-2265.2003.01931.x

15. Ambrosini V, Nanni C, Zompatori M, et al. (68)Ga-DOTA-NOC $\mathrm{PET} / \mathrm{CT}$ in comparison with $\mathrm{CT}$ for the detection of bone metastasis in patients with neuroendocrine tumours. Eur J Nucl Med Mol Imaging. 2010;37(4):722-727. doi:10.1007/s00259-009-1349-9 
16. Lococo F, Perotti G, Cardillo G, et al. Multicenter comparison of 18F-FDG and 68Ga-DOTA-peptide PET/CT for pulmonary carcinoid. Clin Nucl Med. 2015;40(3):e183-9. doi:10.1097/RLU.0000000000 000641

17. Haug AR, Cindea-Drimus R, Auernhammer CJ, et al. Neuroendocrine tumor recurrence: diagnosis with 68Ga-DOTATATE PET/CT. Radiology. 2014;270(2):517-525. doi:10.1148/radiol.13122501

18. Mariniello A, Bodei L, Tinelli C, et al. Long-term results of PRRT in advanced bronchopulmonary carcinoid. Eur J Nucl Med Mol Imaging. 2016;43:441-452.18. doi:10.1007/s00259-015-3190-7

19. Campana D, Ambrosini V, Pezzilli R, et al. Standardized uptake values of (68)Ga-DOTANOC PET: a promising prognostic tool in neuroendocrine tumors. J Nucl Med. 2010;51(3):353-359. doi:10. 2967/jnumed.109.066662

20. Baxi AJ, Chintapalli K, Katkar A, Restrepo CS, Betancourt SL, Sunnapwar A. Multimodality imaging findings in carcinoid tumors: a head-to-toe spectrum. Radiographics. 2017;37(2):516-536. doi:10.1148/ rg.2017160113

21. Carideo L, Prosperi D, Panzuto F, et al. Role of combined [(68)Ga] Ga-DOTA-SST analogues and [(18)F]FDG PET/CT in the management of GEP-NENs: a systematic review. J Clin Med. 2019;8 (7):1032. doi:10.3390/jcm8071032

22. Erasmus JJ, Mc Adams HP, Patz EF Jr, et al. Evaluation of primary pulmonary carcinoid tumors using FDG PET. AJR Am J Roentgenol. 1998;170(5):1369. doi:10.2214/ajr.170.5.9574618

23. Daniels CE, Lowe VJ, Aubry MC, et al. The utility of fluorodeoxyglucose positron emission tomography in the evaluation of carcinoid tumors presenting as pulmonary nodules. Chest. 2007;131 (1):255-260. doi:10.1378/chest.06-0711

24. Chong S, Lee KS, Kim BT, et al. Integrated PET/CT of pulmonary neuroendocrine tumors: diagnostic and prognostic implications. Am J Roentgenol. 2007;188(5):1223-1231. doi:10.2214/AJR.06.0503

25. Abgral R, Leboulleux S, Déandreis D, et al. Performance of (18) fluorodeoxyglucose-positron emission tomography and somatostatin receptor scintigraphy for high $\mathrm{Ki} 67$ ( $\geq 10 \%$ ) well-differentiated endocrine carcinoma staging. J Clin Endocrinol Metab. 2011;96 (3):665-671. doi:10.1210/jc.2010-2022

26. Malczewska A, Kidd M, Matar S, et al. An assessment of circulating chromogranin A as a biomarker of bronchopulmonary neuroendocrine neoplasia: a systematic review and meta-analysis. Neuroendocrinology. 2020;110(3-4):198-216. doi:10.1159/000500525

27. Robelin P, Hadoux J, Forestier J, et al. Characterization, prognosis, and treatment of patients with metastatic lung carcinoid tumors. J Thorac Oncol. 2019;14(6):993-1002. doi:10.1016/j.jtho.2019.02.002

28. Fazio N, Ungaro A, Spada F, et al. The role of multimodal treatment in patients with advanced lung neuroendocrine tumors. J Thorac Dis. 2017;9(Suppl 15):S1501-S1510. doi:10.21037/jtd.20 17.06.14

29. Modlin IM, Lye KD, Kidd M. A 5-decade analysis of 13,715 carcinoid tumors. Cancer. 2003;97(4):934-959. doi:10.1002/ cncr. 11105

30. Yao JC, Hassan M, Phan A, et al. One hundred years after "carcinoid": epidemiology of and prognostic factors for neuroendocrine tumors in 35,825 cases in the United States. J Clin Oncol. 2008;26 (18):3063-3072. doi:10.1200/JCO.2007.15.4377

31. Filosso PL, Ferolla P, Guerrera F, et al. Multidisciplinary management of advanced lung neuroendocrine tumors. J Thorac Dis. 2015;7 (S2):S163-S171. doi:10.3978/j.issn.2072-1439.2015.04.20

32. Peri M, Botteri E, Pisa E, et al. A single-institution retrospective analysis of metachronous and synchronous metastatic bronchial neuroendocrine tumors. J Thorac Dis. 2018;10(7):3928-3939. doi:10. 21037/jtd.2018.06.78

33. Perez EA, Koniaris LG, Snell SE, et al. 7201 carcinoids: increasing incidence overall and disproportionate mortality in the elderly. World J Surg. 2007;31(5):1022-1030. doi:10.1007/s00268-0050774-6
34. Lou F, Sarkaria I, Pietanza C, et al. Recurrence of pulmonary carcinoid tumors after resection: implications for postoperative surveillance. Ann Thorac Surg. 2013;96(4):1156-1162. doi:10.1016/ j.athoracsur.2013.05.047

35. Öberg K, Hellman P, Ferolla P, et al. Neuroendocrine bronchial and thymic tumors: ESMO clinical practice guidelines for diagnosis, treatment and follow-up; ESMO guidelines working group. Ann Oncol. 2012;23 Suppl 7:vii120-3. doi:10.1093/annonc/mds267

36. Phan AT, Oberg K, Choi J, et al. NANETS consensus guideline for the diagnosis and management of neuroendocrine tumors: well-differentiated neuroendocrine tumors of the thorax (includes lung and thymus). Pancreas. 2010;39(6):784-798. doi:10.1097/ MPA.0b013e3181ec1380

37. Bhosale P, Shah A, Wei W, et al. Carcinoid tumours: predicting the location of the primary neoplasm based on the sites of metastases. Eur Radiol. 2013;23(2):400-407. doi:10.1007/s00330-012-2615-y

38. Travis WD, Rush W, Flieder DB, et al. Survival analysis of 200 pulmonary neuroendocrine tumors with clarification of criteria for atypical carcinoid and its separation from typical carcinoid. $\mathrm{Am}$ J Surg Pathol. 1998;22(8):934-944. doi:10.1097/00000478-1998 08000-00003

39. Skuladottir H, Hirsch FR, Hansen HH, et al. Pulmonary neuroendocrine tumors: incidence and prognosis of histological subtypes. A population-based study in Denmark. Lung Cancer. 2002;37 (2):127-135. doi:10.1016/S0169-5002(02)00080-6

40. Ferguson MK, Landreneau RJ, Hazelrigg SR, et al. Long-term outcome after resection for bronchial carcinoid tumors. Eur J Cardiothorac Surg. 2000;18(2):156-161. doi:10.1016/S1010-7940(00)00493-0

41. Filosso PL, Ruffini E, Di Gangi S, et al. Prognostic factors in neuroendocrine tumours of the lung: a single-centre experience. Eur J Cardiothorac Surg. 2014;45(3):521-526. doi:10.1093/ejcts/ ezt442

42. Cardillo G, Sera F, Di Martino M, et al. Bronchial carcinoid tumors: nodal status and long-term survival after resection. Ann Thorac Surg. 2004;77(5):1781-1785. doi:10.1016/j.athoracsur.2003.10.089

43. Rea F, Rizzardi G, Zuin A, et al. Outcome and surgical strategy in bronchial carcinoid tumors: single institution experience with 252 patients. Eur J Cardiothorac Surg. 2007;31(2):186-191. doi:10.10 16/j.ejcts.2006.10.040

44. Filosso PL, Falcoz PE, Solidoro P, et al. ESTS lung neuroendocrine working-group participating centers*. The European Society of Thoracic Surgeons (ESTS) lung neuroendocrine tumors (NETs) database. J Thorac Dis. 2018;10(Suppl 29):S3528-S3532. doi:10.21037/ jtd.2018.04.104

45. Forde PM, Hooker CM, Boikos SA. Systemic therapy, clinical outcomes, and overall survival in locally advanced or metastatic pulmonary carcinoid, a brief report. J Thorac Oncol. 2014;9:414-418. doi:10.1097/JTO.0000000000000065

46. Asamura H, Kameya T, Matsuno Y. Neuroendocrine neoplasms of the lung: a prognostic spectrum. J Clin Oncol. 2006;24(1):70-76. doi: $10.1200 /$ JCO.2005.04.1202

47. Laddha SV, da Silva EM, Robzyk K, et al. Integrative genomic characterization identifies molecular subtypes of lung carcinoids. Cancer Res. 2019;79(17):4339-4347. doi:10.1158/0008-5472.CAN19-0214

48. Simbolo M, Mafficini A, Sikora KO, et al. Lung neuroendocrine tumours: deep sequencing of the four World Health Organization histotypes reveals chromatin-remodelling genes as major players and a prognostic role for TERT, RB1, MEN1 and KMT2D. J Pathol. 2017;241(4):488-500. doi:10.1002/path.4853

49. Fernandez-Cuesta L, Peifer M, Lu X, et al. Frequent mutations in chromatin-remodelling genes in pulmonary carcinoids. Nat Commun. 2014;5:3518. doi:10.1038/ncomms4518

50. Zatelli MC, Minoia M, Martini C, et al. Everolimus as a new potential antiproliferative agent in aggressive human bronchial carcinoids. Endocr Relat Cancer. 2010;17(3):719-729. doi:10.1677/ERC-10-0097 
51. Righi L, Volante M, Rapa I, et al. Mammalian target of rapamycin signaling activation patterns in neuroendocrine tumors of the lung. Endocr Relat Cancer. 2010;17(4):977-987. doi:10.1677/ERC-10-0157

52. Derks JL, Leblay N, Lantuejoul S, et al. New insights into the molecular characteristics of pulmonary carcinoids and large cell neuroendocrine carcinomas, and the impact on their clinical management. J Thorac Oncol. 2018;13(6):752-766. doi:10.1016/j. jtho.2018.02.002

53. Zhang Z, Wang M. PI3K/AKT/mTOR pathway in pulmonary carcinoid tumours. Oncol Lett. 2017;14(2):1373-1378. doi:10.3892/ ol.2017.6331

54. Di Nicolantonio F, Arena S, Tabernero J, et al. Deregulation of the PI3K and KRAS signaling pathways in human cancer cells determines their response to everolimus. J Clin Invest. 2010;120 (8):2858-2866. doi:10.1172/JCI37539

55. Meric-Bernstam F, Akcakanat A, Chen H, et al. PIK3CA/PTEN mutations and Akt activation as markers of sensitivity to allosteric mTOR inhibitors. Clin Cancer Res. 2012;18(6):1777-1789. doi:10.1158/1078-0432.CCR-11-2123

56. Neshat MS, Mellinghoff IK, Tran C, et al. Enhanced sensitivity of PTEN-deficient tumors to inhibition of FRAP/mTOR. Proc Natl Acad Sci US A. 2001;98(18):10314-10319. doi:10.1073/pnas.171076798

57. Gagliano T, Bellio M, Gentilin E, et al. mTOR, p70S6K, AKT, and ERK1/2 levels predict sensitivity to mTOR and PI3K/mTOR inhibitors in human bronchial carcinoids. Endocr Relat Cancer. 2013;20 (4):463-475. doi:10.1530/ERC-13-0042

58. Guba M, von Breitenbuch P, Steinbauer M, et al. Rapamycin inhibits primary and metastatic tumor growth by antiangiogenesis: involvement of vascular endothelial growth factor. Nat Med. 2002;8 (2):128-135. doi:10.1038/nm0202-128

59. Pavel ME, Hainsworth JD, Baudin E, et al. Everolimus plus octreotide long-acting repeatable for the treatment of advanced neuroendocrine tumours associated with carcinoid syndrome (RADIANT-2): a randomised, placebo-controlled, Phase 3 study. Lancet. 2011;378 (9808):2005-2012. doi:10.1016/S0140-6736(11)61742-X

60. Fazio N, Granberg D, Grossman A, et al. Everolimus plus octreotide long-acting repeatable in patients with advanced lung neuroendocrine tumors: analysis of the phase 3, randomized, placebo-controlled RADIANT-2 study. Chest. 2013;143(4):955-962. doi:10.1378/chest.121108

61. Yao JC, Fazio N, Singh S, et al. RAD001 in Advanced Neuroendocrine Tumours, Fourth Trial (RADIANT-4) Study Group. Everolimus for the treatment of advanced, non-functional neuroendocrine tumours of the lung or gastrointestinal tract (RADIANT-4): a randomised, placebo-controlled, phase 3 study. Lancet. 2016;387 (10022):968-977. doi:10.1016/S0140-6736(15)00817-X

62. Fazio N, Buzzoni R, Delle Fave G, et al. Everolimus in advanced, progressive, well-differentiated, non-functional neuroendocrine tumors: RADIANT-4 lung subgroup analysis. Cancer Sci. 2018;109(1):174-181.

63. Bajetta E, Catena L, Fazio N, et al. Everolimus in combination with octreotide long-acting repeatable in a first-line setting for patients with neuroendocrine tumors: an ITMO group study. Cancer. 2014;120(16):2457-2463. doi:10.1002/cncr.28726
64. Bajetta E, Catena L, Pusceddu S, et al. Everolimus in combination with octreotide long-acting repeatable in a first-line setting for patients with neuroendocrine tumors: a 5-year update. Neuroendocrinology. 2018;106(4):307-311. doi:10.1159/000479587

65. Ferolla P, Brizzi MP, Meyer T, et al. Efficacy and safety of long-acting pasireotide or everolimus alone or in combination in patients with advanced carcinoids of the lung and thymus (LUNA): an open-label, multicentre, randomised, Phase 2 trial. Lancet Oncol. 2017;18(12):1652-1664.

66. Yao J, Garg A, Chen D, et al. Genomic profiling of NETs: a comprehensive analysis of the RADIANT trials. Endocr Relat Cancer. 2019;26(4):391-403.

67. Yao JC, Shah MH, Ito T, et al. RAD001 in Advanced Neuroendocrine Tumors, Third Trial (RADIANT-3) Study Group. Everolimus for advanced pancreatic neuroendocrine tumors. $N$ Engl $\mathrm{J} \mathrm{Med}$. 2011;364(6):514-523. doi:10.1056/NEJMoa1009290

68. Chan DL, Yao JC, Carnaghi C, et al. Systemic markers of inflammation in neuroendocrine tumors (NETs) and outcomes with everolimus: a pooled analysis from the randomized, phase 3 RADIANT-3 and RADIANT-4 trials. 15th Annual ENETS Conference for the Diagnosis and Treatment of Neuroendocrine Tumor Disease; 2018(Abstract \#2115).

69. Öberg K, Califano A, Strosberg JR, et al. A meta-analysis of the accuracy of a neuroendocrine tumor mRNA genomic biomarker (NETest) in blood. Ann Oncol. 2020;31(2):202-212. doi:10.1016/j. annonc.2019.11.003

70. Buzzoni R, Carnaghi C, Strosberg J, et al. Impact of prior therapies on everolimus activity: an exploratory analysis of RADIANT-4. Onco Targets Ther. 2017;16(10):5013-5030. doi:10.2147/OTT.S142087

71. Faggiano A, Di Maio S, Mocerino C, et al. Therapeutic sequences in patients with grade 1-2 neuroendocrine tumors (NET): an observational multicenter study from the ELIOS group. Endocrine. 2019;66 (2):417-424. doi:10.1007/s12020-019-01894-0

72. Panzuto F, Rinzivillo M, Fazio N, et al. Real-world study of everolimus in advanced progressive neuroendocrine tumors. Oncologist. 2014;19(9):966-974. doi:10.1634/theoncologist.2014-0037

73. Pavel M, O'Toole D, Costa F, et al. ENETS consensus guidelines update for the management of distant metastatic disease of intestinal, pancreatic, bronchial neuroendocrine neoplasms (NEN) and NEN of unknown primary site. Neuroendocrinology. 2016;103(2):172-185. doi:10.1159/000443167

74. Moreno A, Akcakanat A, Munsell MF, Soni A, Yao JC, MericBernstam F. Antitumor activity of rapamycin and octreotide as single agents or in combination in neuroendocrine tumors. Endocr Relat Cancer. 2008;15(1):257-266. doi:10.1677/ERC-07-0202

75. Ito T, Lee L, Jensen RT. Treatment of symptomatic neuroendocrine tumor syndromes: recent advances and controversies. Expert Opin Pharmacother. 2016;17(16):2191-2205. doi:10.1080/14656566.2016.12 36916

76. Ito T, Lee L, Jensen RT. Carcinoid-syndrome: recent advances, current status and controversies. Curr Opin Endocrinol Diabetes Obes. 2018;25(1):22-35. doi:10.1097/MED.0000000000000376
Lung Cancer: Targets and Therapy

\section{Publish your work in this journal}

Lung Cancer: Targets and Therapy is an international, peerreviewed, open access journal focusing on lung cancer research, identification of therapeutic targets and the optimal use of preventative and integrated treatment interventions to achieve improved outcomes, enhanced survival and quality of life for the cancer patient. Specific topics covered in the journal include: Epidemiology, detection and screening; Cellular research and biomarkers; Identification of biotargets and agents with novel mechanisms of action; Optimal clinical use of existing anticancer agents, including combination therapies; Radiation and surgery; Palliative care; Patient adherence, quality of life, satisfaction; Health economic evaluations. 